\title{
Popliteal Entrapment Syndrome as a Cause of Chronic Lower Extremity Pain in a 16-Year Old
}

\author{
Mackenzie N. Naert ${ }^{1}$, Brittany Glassberg ${ }^{2}$, Daniel Han ${ }^{3}$, Joseph Truglio ${ }^{2}$ \\ 1. Obstetrics and Gynecology, Brigham and Women's Hospital, Harvard Medical School, Boston, USA 2. Internal \\ Medicine-Pediatrics, Icahn School of Medicine at Mount Sinai, New York, USA 3. Vascular Surgery, Icahn School of \\ Medicine at Mount Sinai, New York, USA
}

Corresponding author: Brittany Glassberg, brittany.glassberg@icahn.mssm.edu

\begin{abstract}
Popliteal entrapment syndrome is an uncommon cause of intermittent claudication in young patients lacking atherosclerotic risk factors. ZS is a 16-year-old cisgender female with type 1 diabetes complicated by microalbuminuria, obesity (body mass index $(\mathrm{BMI})=45.86 \mathrm{~kg} / \mathrm{m}^{2}$ ), and a history of perinatal stroke with residual right-sided hemiparesis, who presented with six months of worsening bilateral, exertional lower extremity pain. Common causes of chronic bilateral lower extremity pain include peripheral vascular disease and diabetic neuropathy. Less common etiologies include trauma, infection, or juvenile idiopathic arthritis. Given her risk factors, the patient's pain was initially managed as a diabetic neuropathy with pregabalin. Symptoms failed to improve, and she re-presented with positional coolness of the right lower extremity, diminished pulses of the bilateral lower extremities, and weakness in her toes. CT angiography demonstrated occlusion of the right distal superficial femoral and popliteal arteries and diffused tibial disease. Ultimately, the patient was discovered to have right-sided femoral-popliteal occlusion, and she required urgent femoraltibial bypass. Despite an initial improvement in symptoms postoperatively, she continued to have lower extremity pain and recurrent arterial thrombi, even with antiplatelet and anticoagulation therapy. Eventually, the patient required a right-sided below the knee amputation. This case highlights the high index of suspicion that clinicians must have in young patients with lower extremity pain, both with and without atherosclerotic risk factors, as early intervention facilitates better outcomes. Introduction
\end{abstract}

Received 10/12/2020 Review began 11/19/2020 Review ended 03/03/2021 Published 03/05/2021

() Copyright 2021 Naert et al. This is an open access article distributed under the terms of the Creative Commons Attribution License CC-BY 4.0., which permits unrestricted use, distribution, and reproduction in any medium, provided the original author and source are credited.
Categories: Cardiac/Thoracic/Vascular Surgery, Internal Medicine, Pediatrics Keywords: popliteal entrapment, med-peds, adolescent medicine

\section{Introduction}

Popliteal entrapment syndrome is an uncommon cause of intermittent claudication in younger patients lacking atherosclerotic risk factors. The estimated incidence of the diagnosis is $0.17-3.5 \%$ [1]. For this reason, popliteal entrapment syndrome is often a delayed diagnosis [2]. Here we present the case of an adolescent diagnosed with popliteal entrapment syndrome after being initially diagnosed and treated for diabetic neuropathy in the setting of poorly-controlled type 1 diabetes. This case demonstrates the importance of having a broad differential for claudication in a young adult.

\section{Case Presentation}

\section{Patient Information}

ZS is a 16-year-old female with Type 1 diabetes diagnosed at age 11, complicated by microalbuminuria, obesity (body mass index $(\mathrm{BMI})=45.86 \mathrm{~kg} / \mathrm{m}^{2}$ ), and perinatal history of stroke with residual right-sided hemiparesis, who presented with six months of worsening bilateral, exertional lower extremity pain. She described a burning pain associated with numbness and tingling, worse with ambulation and when supine. The pain was progressive and resulted in difficulty walking and multiple school absences. The patient has a history of depression with cutting behaviour; she denies suicidal and homicidal ideations. Family history is significant for type 1 diabetes mellitus and Hashimoto's thyroiditis in her younger sister and her mother's coronary artery disease. Social history is significant for recent tobacco use initiation (1-4 cigarettes per day) and marijuana use (1-2 times per week). She denies alcohol consumption. The patient uses art as a mechanism for coping with significant pain and medical conditions (Figure 1). The patient's medication regimen consists of a continuous insulin pump, Metformin $500 \mathrm{mg}$ daily, and Duloxetine $60 \mathrm{mg}$ daily. 


\section{Cureus}

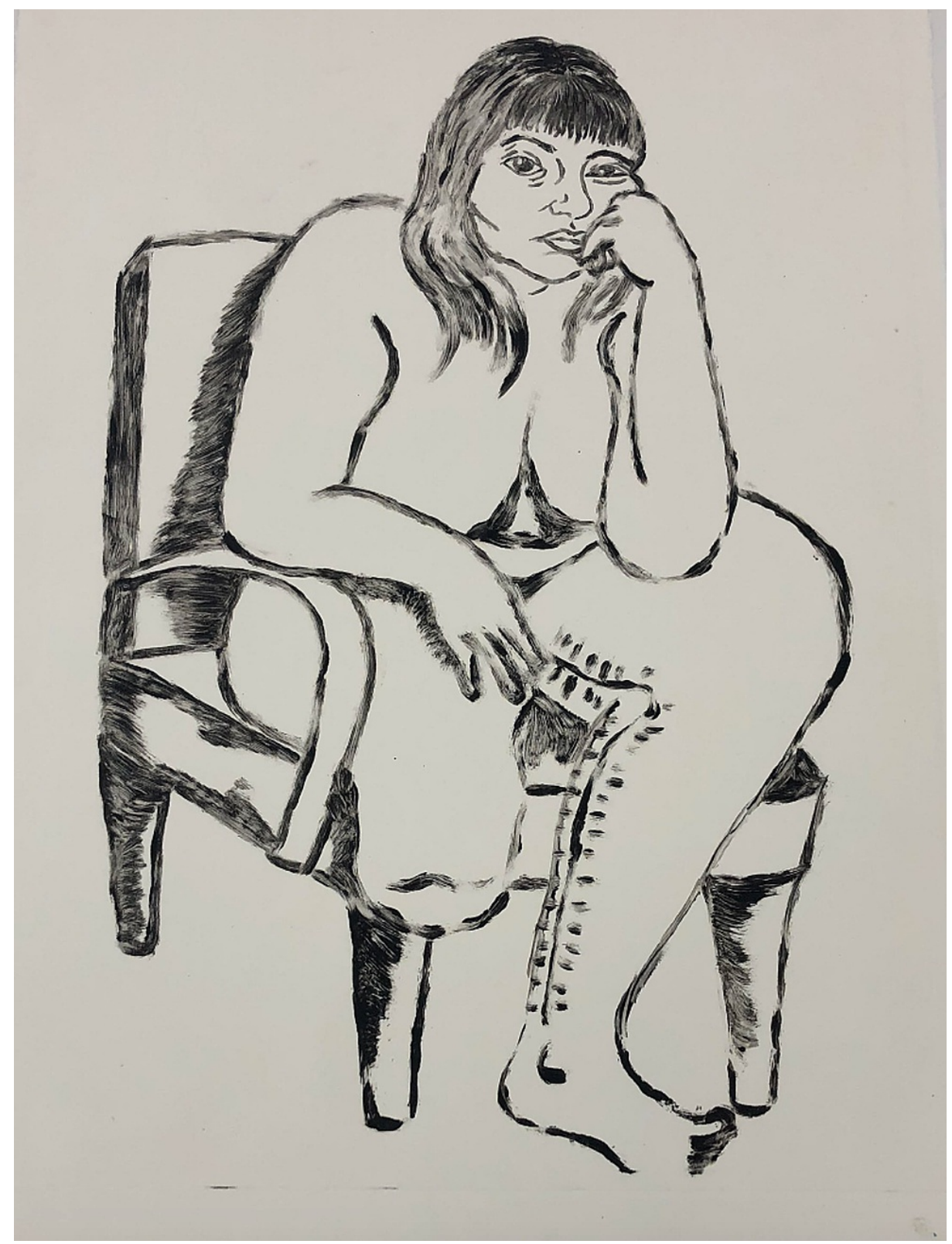

\section{FIGURE 1: Self-portrait of ZS created during post-operative period}

\section{Clinical Findings}

On initial presentation, the patient's vital signs were within normal limits. Her BMI was $45.86 \mathrm{~kg} / \mathrm{m}^{2}$. She was a well-appearing, obese adolescent in no acute distress. Physical exam was notable for intact pedal pulses bilaterally and intact sensation to light touch and vibration in both feet. Her right first toe was erythematous and edematous with onychocryptosis. There were early bilateral stage 1 linear heel ulcers. Her neurological exam was significant for the distal flaccid weakness of the right hand and foot with an upgoing Babinksi on the right, consistent with perinatal stroke history. There was no muscular atrophy or fasciculation. She had a right circumducting hemiparetic gait.

The patient's initial labs were significant for an elevated Hemoglobin A1c (HbA1c) 8.9\% (normal <6\%), thyroid-stimulating hormone (TSH) level within normal limits (2.96mIU/L; reference $0.55-4.78)$, and Vitamin B12 level within normal limits (327ng/mL; reference 211-911ng/mL). See Table 1 for a comprehensive list of laboratory evaluations. She was referred to neurology for neuromuscular and electrophysiological evaluation and was found to have a distal sensory axonal polyneuropathy. Given the elevated Hemoglobin A1c and her sensory polyneuropathy, she was initially thought to have diabetic neuropathy and managed as such. 


\section{Cureus}

\begin{tabular}{|c|c|c|c|c|c|}
\hline \multicolumn{3}{|c|}{ Hematologic \& Endocrinologic Studies } & \multicolumn{3}{|l|}{ Rheumatologic Studies } \\
\hline Component & Value & Normal & Component & Value & Normal \\
\hline D-dimer & $\begin{array}{l}1.04 \\
\mu g / m L(H)\end{array}$ & $<0.50 \mu \mathrm{g} / \mathrm{m} /$ & C Reactive Protein HS & $18.2 \mathrm{mG} / \mathrm{L}(\mathrm{H})$ & 0.0-5.0 mG/L \\
\hline Prothrombin Time & $13.6 \mathrm{~s}$ & $11.8-14.3 \mathrm{~s}$ & $\begin{array}{l}\text { Erythrocyte Sedimentation } \\
\text { Rate }\end{array}$ & $\begin{array}{l}29 \mathrm{~mm} / \text { hour } \\
\text { (H) }\end{array}$ & $0-15 \mathrm{~mm} / \mathrm{hour}$ \\
\hline INR & 1.1 & $0.9-1.1$ & Cystatin C & $0.93 \mathrm{mg} / \mathrm{L}$ & $\begin{array}{l}0.50-1.00 \\
\mathrm{mg} / \mathrm{L}\end{array}$ \\
\hline $\begin{array}{l}\text { Activated Partial Thromboplastin } \\
\text { Time }\end{array}$ & $39.1 \mathrm{~s}(\mathrm{H})$ & $25.0-35.0 \mathrm{~s}$ & Anti-human TTG-IgA & $1 \mathrm{mg} / \mathrm{dL}$ & $<4$ mg/dL \\
\hline T4 (Thyroxine) Total & $7.1 \mathrm{mcg} / \mathrm{dL}$ & $\begin{array}{l}5.7-11.4 \\
\mathrm{mcg} / \mathrm{dL}\end{array}$ & ANA & Negative & Negative \\
\hline T4 (Thyroxine) Free & $1.06 \mathrm{mcg} / \mathrm{dL}$ & $\begin{array}{l}0.80-1.16 \\
\mathrm{mcg} / \mathrm{dL}\end{array}$ & Lupus Anticoagulant & Negative & Negative \\
\hline Thyroglobulin Ab & $<20.0 \mathrm{lU} / \mathrm{ml}$ & $0-40.0 \mathrm{lU} / \mathrm{ml}$ & Anti-Thrombin III & $66 \%(\mathrm{~L})$ & $81-113 \%$ \\
\hline Anti-TPO Ab & $20.6 \mathrm{IU} / \mathrm{ml}$ & $0-35.0 \mathrm{lU} / \mathrm{ml}$ & Factor V Leiden & Negative & Negative \\
\hline Thyroid Stimulating Hormone & $\begin{array}{l}2.959 \\
\mathrm{ulU} / \mathrm{mL}\end{array}$ & $\begin{array}{l}0.34-5.60 \\
\text { ulU } / \mathrm{mL}\end{array}$ & C-Anca & Negative & Negative \\
\hline Vitamin B12 & $327 \mathrm{ng} / \mathrm{mL}$ & $211-911 \mathrm{ng} / \mathrm{mL}$ & P-Anca & Negative & Negative \\
\hline Homocysteine & $6.3 \mathrm{umol} / \mathrm{L}$ & 5.0-15.0 umol/L & Antiphospholipid lgG & 7 units & $0-14$ units \\
\hline Protein C Activity & $121 \mathrm{IU} / \mathrm{dL}$ & 75-133 IU/dL & Antiphospholipid lgM & $24(H)$ units & $0-14$ units \\
\hline Protein S Activity & 52 lU/dL & 52-151 IU/dL & $\begin{array}{l}\text { MTHFR C677T/A1298C } \\
\text { Mutation }\end{array}$ & Negative & Negative \\
\hline
\end{tabular}

\section{TABLE 1: Laboratory evaluation in search for etiology of popliteal entrapment syndrome}

H: high, INR: international normalized ratio, C-Anca: C-Antineutrophil cytoplasmic antibodies, P-Anca: P-Antineutrophil cytoplasmic antibodies, Ab: antibodies, Anti-TPO Ab: anti-thyroid peroxidase antibodies, Anti-human TTG-IgA: Anti-human tissue transglutaminase immunoglobulin A, IgG: Immunoglobulin G, IgM: Immunoglobulin M

She was prescribed Pregabalin 100mg BID alleviate pain, to which she had minimal response. One month later, she presented with positional coolness in her right lower extremity (see Table 2 for specific timeline). On exam, she was found to have diminished pulses in bilateral lower extremities and difficulty moving her toes. Her extremities were warm, the sensation was intact, and the neurological exam was grossly intact. Her brachial ankle index at the time of admission was 0.35 right lower extremity and 0.45 left lower extremity. She was found on computerized tomography (CT) angiography to have occlusion of the right distal superficial femoral and popliteal arteries and diffuse tibial disease (Figure 2). 


\section{Cureus}

Relevant Past Medical History and Interventions

ZS is a 16-year-old female with Type 1 diabetes diagnosed at age 11 complicated by microalbuminuria, obesity $\left(\mathrm{BMI}=45.86 \mathrm{~kg} / \mathrm{m}^{2}\right)$, and a history of prenatal stroke with residual right-sided hemiparesis, who presented with 6 months of worsening bilateral, exertional lower extremity pain.

\begin{tabular}{|c|c|c|c|}
\hline Date & Presentation \& Evaluation & Diagnostic Testing \& Results & Interventions \\
\hline $\begin{array}{l}\text { August } \\
20 \text { th, } \\
2015\end{array}$ & $\begin{array}{l}\text { Initial presentation to the } \\
\text { Emergency Department at an } \\
\text { outside hospital for pain with } \\
\text { ambulation x } 6 \text { months }\end{array}$ & $\begin{array}{l}\text { HbA1c (elevated at } 8.9 \% \text { ) B12 } \\
\text { (within normal limits at } 327 \\
\mathrm{ng} / \mathrm{mL} \text { ) TSH (within normal } \\
\text { limits at } 2.96 \mathrm{mlU} / \mathrm{L} \text { ) }\end{array}$ & Neurology Referral \\
\hline $\begin{array}{l}\text { October } \\
15 \text { th, } \\
2015\end{array}$ & $\begin{array}{l}\text { Referral to neurology for } \\
\text { presumed diabetic neuropathy }\end{array}$ & $\begin{array}{l}\text { Electrophysiologic testing } \\
\text { consistent with distal sensory } \\
\text { axonal polyneuropathy }\end{array}$ & Pregabalin 100mg BID \\
\hline $\begin{array}{l}\text { October } \\
28,2015\end{array}$ & $\begin{array}{l}\text { Presented to the Emergency } \\
\text { Department with first episode of } \\
\text { acute ischemia. Admitted to } \\
\text { Pediatric Intensive Care Unit. }\end{array}$ & $\begin{array}{l}\text { CT angiography } \\
\text { demonstrating right-sided } \\
\text { arterial thrombus }\end{array}$ & $\begin{array}{l}\text { Semi-urgent Popliteal Bypass Surgery: Right } \\
\text { superior femoral artery to proximal anterior tibial } \\
\text { artery bypass and embolectomy of the bypass }\end{array}$ \\
\hline $\begin{array}{l}\text { November } \\
2015- \\
\text { January } \\
2017\end{array}$ & $\begin{array}{l}\text { Presented to Emergency } \\
\text { Department for recurrent } \\
\text { claudication }\end{array}$ & $\begin{array}{l}\text { CT angiogram demonstrates } \\
\text { recurrent bilateral thrombi }\end{array}$ & $\begin{array}{l}\text { Multiple revascularization procedures including } \\
\text { bypass surgeries (6), embolectomies/ } \\
\text { thrombectomy (2), thrombolysis, percutaneous } \\
\text { transluminal angioplasty \& stent placement }\end{array}$ \\
\hline $\begin{array}{l}\text { May 5th, } \\
2017\end{array}$ & $\begin{array}{l}\text { Presented to Emergency } \\
\text { Department for continued } \\
\text { recurrent claudication }\end{array}$ & $\begin{array}{l}\text { CT angiogram demonstrates } \\
\text { occluded/failed femoral } \\
\text { artery-anterior tibial bypass }\end{array}$ & $\begin{array}{l}\text { Right below the knee amputation. Follow-up search } \\
\text { for etiology }\end{array}$ \\
\hline
\end{tabular}

\section{TABLE 2: Timeline of events and interventions}

CT: Computerized tomography, HbA1c: Hemoglobin A1c, TSH: Thyroid-stimulating hormone 


\section{Cureus}

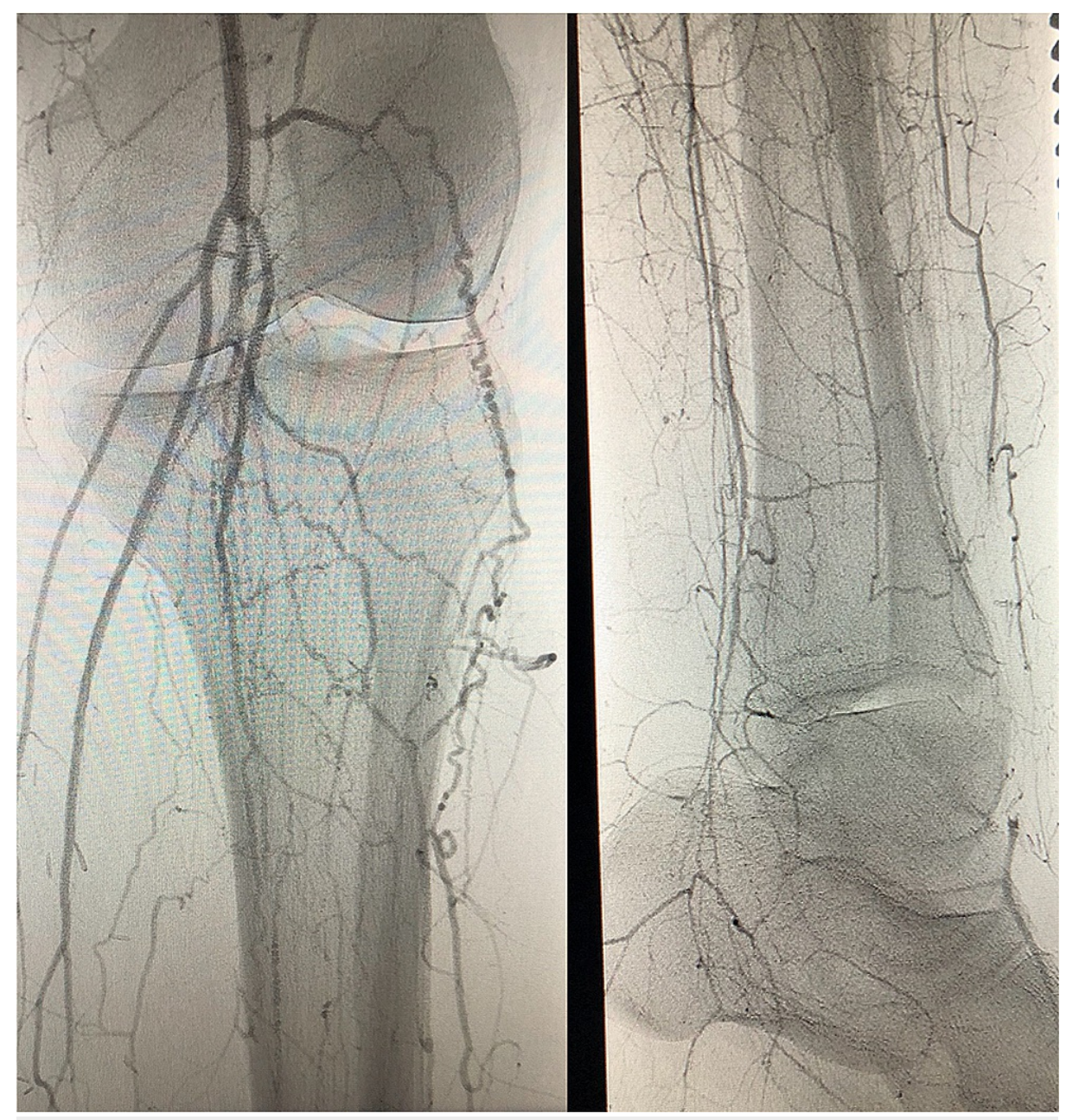

\section{FIGURE 2: Right Lower Extremity CT Angiogram April 2017}

Left: Right distal superficial femoral and popliteal artery collateral circulation development. Right: Right lower extremity collateral circulation to a level of dorsalis pedis artery.

The patient was taken to the operating room for a thromboembolectomy and right superior femoral artery to proximal anterior tibial artery bypass. Over the next 18 months, the post-operative course was complicated by recurrent bilateral thrombi requiring six popliteal bypass surgeries and two embolectomies. Subsequent workup was unrevealing for a hypercoagulable state (including negative ANA, lupus anticoagulant, antithrombin III activity, and Factor V Leiden mutations) or vasculitis (including negative c-ANCA and pANCA; see Table 2). Despite an initial improvement in symptoms, she continued to have recurrent thrombosis of her bypass even with antiplatelet and anticoagulation therapy, worsening ischemic rest pain and foot ulcerations, ultimately requiring a right-sided below the knee amputation. Medical management postoperatively was focused on clot-prevention with aspirin $81 \mathrm{mg}$ and rivaroxaban $20 \mathrm{mg}$ daily. Her pain was managed with gabapentin 600mg BID and methadone $2.5 \mathrm{mg}$ BID. Her recovery was complicated by chronic pain syndrome and delayed wound closure requiring multiple debridements. The patient is currently awaiting prosthesis placement, and she is engaged in trauma-informed care, a comprehensive therapeutic approach centred on supporting patients as they process adverse experiences [3].

\section{Discussion}

Popliteal entrapment syndrome is a rare condition in which the tendons and muscles near the knee compress the popliteal artery, restricting blood flow to the lower leg $[2,4]$. The incidence of popliteal entrapment syndrome is likely underestimated due to underdiagnosis, but recent reports estimate between $0.17 \%$ and $3.5 \%$ [2]. The condition is most commonly caused by a congenital anomaly that causes the medial or lateral gastrocnemius head to shift towards the popliteal artery during knee flexion, compressing the artery [2,4-6]. It is most commonly seen in young men (85\% of cases are male) [2], particularly in bicyclists, runners, and active military personnel ( $60 \%$ of cases occur in male athletes $<30$ years old) [2]. It is hypothesized that repetitive overuse gradually leads to the thickening of vessel walls in the popliteal artery due to excessive pressure from the muscle belly [6]. 
The embryonic development of the structures of the popliteal fossa accounts for the anatomic variability of this diagnosis. Both the popliteal artery and medial head of the gastrocnemius muscle develop at the same embryological time point. Anomalies relating to the popliteal artery's position, medial head of the gastrocnemius and popliteus muscles can account for the etiology of this syndrome [2]. Despite these anatomic variants, many people born with this disease's congenital form are often asymptomatic, suggesting a multifactorial etiology of the disease. It is thought that changes related to the gastrocnemius muscle, particularly while running or marching, cause muscle hypertrophy with external compression and impingement of the popliteal artery [2]. Notably, unlike most arterial occlusion causes, popliteal entrapment syndrome is not associated with an increased risk of cardiovascular disease [5-7].

While most patients do not have clinically significant disease, those who do have symptoms typically report deep calf pain following intense exercise involving ankle dorsiflexion and plantarflexion, resembling claudication, usually within the 2nd decade of life. Further, patients may experience paresthesias across the proximal posterior calf during exercise, followed by pale, discoloured feet and toes. Physical examination is usually normal, with possible hypertrophy of the calf muscles $[2,4,5]$. Chronic repeated arterial compression can lead to acute thrombus formation and a presentation with acute limb-threatening ischemia, as was the case for ZS [2]. This case is unique because the patient presented here is both female and a non-athlete, different from the majority of patients with the disease. Perhaps an unknown or multifactorial etiology, including her history of right-sided paresis and family history of CAD, exists in our patient and others like her.

Workup for popliteal entrapment syndrome includes assessing distal pulses and ankle-brachial index, followed by Doppler ultrasound and compartmental pressure measurement, with an option for CT angiogram and MRI. Confirmed diagnosis of popliteal entrapment requires demonstration of abnormal muscle attachments on imaging; without this result, it is referred to as functional popliteal entrapment syndrome $[1,2]$. Newer studies highlight the advantage of intravascular ultrasound in diagnosis, as this novel imaging modality allows for specific localization of compression and can assist in operative planning.

Current recommendations for management include surgical myotomy or botulinum toxin A injections. By the time many patients seek medical care, they are typically highly symptomatic, and the preferred management involves decompression of the entrapped artery by the release of abnormal muscle connections. Arterial reconstruction or revascularization is only performed if there is evidence of arterial injury or thrombosis. The preferred surgical therapy is decompression of the entrapped artery and reconstruction with vein graft interposition $[2,4,5]$. Thromboendarterectomy is the second line $[7,8]$.

\section{Conclusions}

This case highlights the high index of suspicion that clinicians must have in young patients with claudication. The majority of patients with popliteal entrapment syndrome present late in the disease course, and ZS was diagnosed after 16 months of symptoms. The strongest predictive factor for successful treatment of popliteal entrapment syndrome is early diagnosis and timely management, underscoring the importance of recognizing symptom subtleties in this disease.

\section{Additional Information \\ Disclosures}

Human subjects: Consent was obtained or waived by all participants in this study. Conflicts of interest: In compliance with the ICMJE uniform disclosure form, all authors declare the following: Payment/services info: All authors have declared that no financial support was received from any organization for the submitted work. Financial relationships: All authors have declared that they have no financial relationships at present or within the previous three years with any organizations that might have an interest in the submitted work. Other relationships: All authors have declared that there are no other relationships or activities that could appear to have influenced the submitted work.

\section{Acknowledgements}

Thank you to ZS for letting us participate in your care and for continuing to inspire us with your spirit and perseverance.

\section{References}

1. Edmonds M: Vascular disease in the lower limb in type I diabetes . Cardiovasc Endocrinol Metab. 2019, 8:3946. 10.1097/XCE.0000000000000168

2. Davis DD, Shaw PM: Popliteral artery entrapment syndrome. Treasure Island (FL): StatPearls Publishing, FL; 2020.

3. Oral R, Ramirez M, Coohey C, et al.: Adverse childhood experiences and trauma informed care: the future of health care. Pediatr Res. 2015, 79:227-233. 10.1038/pr.2015.197

4. Corneloup L, Labanere C, Chevalier L, et al.: Presentation, diagnosis, and management of popliteal artery entrapment syndrome: 11 years of experience with 61 legs. Scand J Med Sci Sports. 2017, 28:517-523. 


\section{Cureus}

10.1111/sms.12918

5. Rooke TW, Hirsch AT, Misra S, et al.: Management of patients with peripheral artery disease (compilation of 2005 and 2011 ACCF/AHA guideline recommendations): a report of the American College of Cardiology Foundation/American Heart Association task force on practice guidelines. J Am Coll Cardiol. 2013, 61:1555. 10.1016/j.jacc.2013.01.004

6. Shahi N, Arosemena M, Kwon J, Abai B, Salvatore D, DiMuzio P: Functional popliteal entrapment syndrome: a systematic review of diagnosis and management. J Vasc Surg. 2017, 65:114-115.

10.1016/j.avsg.2018.12.105

7. Boniakowski AE, Davis F, Campbell D, Khaja M, Gallagher KA: Intravascular ultrasound as a novel tool for the diagnosis and targeted treatment of functional popliteal entrapment. J Vasc Surg Cases Innov Tech. 2017, 3:74-78. 10.1016/j.jvscit.2017.02.006

8. Schurmann G, Mattfeldt T, Hofmann W, Hohenberger P, Allenberg JR: The popliteal entrapment syndrome: presentation, morphology and surgical treatment of 13 cases. Eur J Vasc Surg. 1990, 4:223-231.

10.1016/S0950-821X(05)80199-9 